\title{
Amplifier Device
}

National Cancer Institute

\section{Source}

National Cancer Institute. Amplifier Device. NCI Thesaurus. Code C49825.

An electronic device designed to take an input signal and output an increased signal strength. 